\title{
Brave New World: Can Positive Developments in Safety Science and Practice also have Negative Sides?
}

\author{
Carsten Busch ${ }^{1, *}$ \\ ${ }^{1}$ Mind The Risk \& Politidirektoratet, Norway
}

\begin{abstract}
The last few decades have brought advances and positive developments in safety. Traditional approaches to prevent accidents are supplemented and enhanced with approaches that stress positive instead of negatives, that humanize, that are more systemic, that appreciate complexity, context, variability and adaptability. One must wonder, however, are there any negative effects we should be wary about? This paper reflects about this question by using five mechanisms: 1) the language we use to discuss things, 2) the emergence of professional tribalism, 3) the evolution of ideas and concepts, 4) side-effects of success, and 5) ethical dilemmas we may encounter in our everyday work. New developments will come with by-products that we cannot prevent. Suggestions to deal with this include open, critical minds, and awareness of possible pitfalls. Being prepared to deal with the inevitable variations that will occur is important, as are balanced approaches in how professionals discuss and handle concepts and tools.
\end{abstract}

Keywords: New view; Ethics; Professionalism; Critical thinking.

\section{INTRODUCTION}

Building on the work of pioneers like Reason, Rasmussen, and Woods, the last few decades have brought advances and positive developments in safety. Traditional approaches to prevent accidents (Heinrich, 1931; Bird \& Loftus, 1976; Petersen, 2001) are supplemented and enhanced with approaches that stress positives instead of negatives, that explore why safety happens instead of accidents, that humanize, that are more systemic, that enhance resilience and system performance, that appreciate complexity, context, variability and adaptability (Dekker, 2014; 2018; Hollnagel, 2009; 2014; Woods, 2015).

Having the solid, mechanistic tools of yesterday and these rich new approaches at our disposal should enable us to head into a bright future. One must wonder, however, are there any negative by-products we should be wary about? What if, like in Huxley's novel (1932), what we perceive as blessings contain hidden dangers? The wise thing to do is to consider those. After all, things tend to come with side effects. Even (or maybe, especially) positive developments.

This paper aims to share some reflections. For the purpose of this paper, some side effects will be discussed by using some mechanisms that safety professionals and scholars should be aware of, to handle problems that may arise. These mechanisms are interconnected and affect each other. In no way should this be regarded as some kind of definite analysis; rather it is a loose framework that the author has found to be useful for reflection, and as a way to categorize observations from safety literature, professional debates and discussions in a variety of forums. The mechanisms to reflect upon are (1) the language we use to discuss things, (2) the emergence of professional tribalism, (3) the evolution of ideas and concepts, (4) side-effects of success, and (5) ethical dilemmas we may encounter in our everyday work.

\footnotetext{
* Corresponding author: +47 91655 036, Carsten@mindtherisk.com
} 


\section{LANGUAGE}

Language is one of our most powerful tools. People interact all the time, often through written or verbal language. While the major part of our communication is without words (attitude, expression, actions etc.) it is important to pay attention to our language to avoid misunderstandings or misinterpretations (Busch, 2016).

\subsection{Framing, Value and Judgement}

How we talk about things shapes our thoughts and the thoughts of others with whom we interact. This concerns not only what we say, but also how we say it, what we call things, and how we phrase them. Through our language, we frame, we suggest, and we influence judgements whether we want to or not. The 'new view' of safety encourages to stay away from normative, judgemental language (Dekker, 2002), yet we put value statements in much of our communication and use normative language all the time, often unknowingly. It just happened in a relatively mild form when certain approaches were labelled as 'new'. While 'new' can be seen objectively as merely a comparison of something coming after something else that went before, we tend to attach a value judgement to it. In everyday language, we usually regard 'new' as 'better' than something 'old', and automatically we attribute an 'improved' or 'superior' label to it. Humans appear to have an automatic preference for what is 'new' (Harari, 2011).

The same effect occurs when talking about Safety I and Safety II (Hollnagel, 2014). After all, a 2.0 version is seen as "as a superior or more advanced version of an original concept, product, service, etc." (Oxford Dictionaries). From there it is a small step to talk about "dated concepts" and dismiss traditional approaches like dominos and the Swiss Cheese Model. After all, "The thinking on which it is based is getting on in age - soon a century" (Dekker, 2014, p.123). Other authors (e.g. Marriott, 2018; Gesinger, 2018; Long, 2018) make similar points, but hardly ever do they elaborate, just as if age were a self-explanatory disqualifier. Being 'old' in itself should not be a relevant argument, of course. Newton's laws and Pythagoras' theorem are even older. Is that a reason to question them?

A nasty side effect of feeling superior (even though this feeling is unwarranted) is that it may shut down possibilities for learning. After all, if you already know better, nothing is to be gained from that other thing. You close your mind because you already know (Tetlock \& Gardner, 2015). This ignores, of course, the problem of how to determine what is 'better'. Even when 'new is better' in some aspects, that does not automatically mean that it (fully) replaces or disqualifies 'old' approaches. Generally, 'better' depends upon the application, situation and circumstances. An analysis using FRAM (Functional Resonance Analysis Method) (Hollnagel, 2012) may be much richer and better capture the complex reality, but when you are pressed for time or dealing with a rather simple problem, like why the light is not working, ' 5 Why' may not be so bad after all. Not only may this be a trade-off between various objectives, like efficiency and thoroughness (ETTO) (Hollnagel, 2009); there is also a matter of diminishing returns - better knowledge of all circumstances does not always improve the desired result.

\subsection{Opposites, Extremes and Absolutes}

We need language to communicate our views. Extremes, opposites and contrasts are powerful tools in our communication to illustrate, educate, convince and persuade (Cialdini, 1984; Pink, 2012). We can see this for example at work in the Safety I and Safety I/ book. The first four chapters - half the book - are used to decompose and point out downsides of traditional methods, before offering a 'new view', Safety II (Hollnagel, 2014). By contrasting and positioning 'new' approaches against the drawbacks of something 'old' the added value becomes clear.

While being a powerful tool of communication, this approach may also over-communicate the message, like one is speaking in CAPS LOCK. This may lead practitioners into black and white 
thinking, believing that they need to choose between either one or the other approach (e.g. old vs new, Safety I vs Safety II, traditional vs differently) instead of seeing them as complementary ways to work on safety (Hollnagel, 2014). This kind of binary thinking may lead to throwing out the baby with the bathwater, and wholesale rejection of traditional approaches, e.g. when adepts of the "new view' reject RCA (root cause analysis), or the use of BowTies. Instead of dismissing and preaching to "stop using", a better approach may be teaching about the limitations of approaches. Imperfect tools can be very useful and are often perfectly usable within the proper context (Hale, 2014; Townsend, 2014)

Another negative thing is that stressing opposites and extremes may not add to the discussion, but rather narrow it down. If you attack or dismiss another approach instead of questioning it critically, the primary reaction will usually be defensive. From there, it is hard to move to a fruitful discussion. This will especially be the case when one enters the debate with bold statements and absolutes. Absolutes are almost never right, and easy to debunk (one needs only to find the one exception) and therefore easy to defend against. This can inhibit the desired change and improvement. Therefore, even though they are illustrative, extreme positions may not only lead to enhancement and improvement, but also polarisation and separation (Shorrock, 2014).

There is also an 'external' problem to this, outside of the safety community. If safety professionals are seen arguing among each other, this may weaken the credibility of the profession and leave others wondering whether one can use safety professionals for anything practical? The reputation of health and safety is not too good to start with - which, of course, is one reason why new approaches are necessary (Dekker, 2018).

\section{TRIBALISM}

\subsection{From Distinction to Polarisation}

As we saw in section 2 above, language helps us to create distinctions between different approaches. These distinctions can be necessary to establish something new. Distinctions can help to get a new movement going, to draw attention, to illustrate and to convince people of the added value. The creation of a movement of like-minded people who identify themselves with the new thoughts can be a good thing because it can provide practitioners and academics with a network. There they can develop, peer-review, test and improve ideas and approaches, and share experiences. It provides them with a safe environment where non-traditional approaches can be discussed.

In Dutch, there is a saying: "waar je mee omgaat, word je mee besmet". The closest English translation would be "who keeps company with the wolf will learn how to howl". As we immerse ourselves in 'new views', read more about it, listen to speakers, attend conferences and workshops, listen to podcasts and so on, this will shape a new reality for us that becomes more and truer and skewers our perception into one direction (Lotto, 2017). At the same time, this can also lead to extremes. There can be a thin line between distinction and polarisation, the formation of tribes, and the rise of gurus, zealots and fundamentalists. Research on the subject seems to be limited ${ }^{\dagger}$, but many will have heard stories about or experienced recent converts, be it to a kind of religion or ending an addiction (smoking, drinking, etc.). They tend to be the most fanatic and show a strong devotion to their new belief system. Safety practitioners are assumed to be rational, but they are not immune to this effect.

Even in less extreme forms, there may be a growing sense of 'us and them' that rather highlights the differences between approaches and beliefs than the common goal of improving safety. A sense of 'us and them' can quickly turn into 'us versus them'. Within a 'tribe' then certain habits, language and expected behaviours can develop. If you want to be part of the in-crowd, you are expected to conform to unwritten rules that govern the movement; what to read, the jargon and methods to use, what to approve of and what to 'frown upon'. Like when the Safety Differently

\footnotetext{
${ }^{\dagger}$ https://bycommonconsent.files.wordpress.com/2010/02/pond-smith-sahgal-clement-zeal-of-convert-asre09.pdf
} 
website announces that "bashing safety initiatives that are based on constraining people's capacities will be a frequent ingredient" .

\subsection{Guruism and New Myths}

As a movement establishes itself and people start identifying themselves with the approaches, you will see that there are leaders and followers. Naturally, some thinkers point the way with their ideas. This is enhanced by the rise of new 'safety gurus', who may gain their guru status easier than ever before. After all, these days, thinkers are no longer limited to books, papers and conferences. Thanks to modern technology like social media, blogs, podcasts and YouTube clips, they can reach a wide audience, reach them fast, and reach them through a low threshold.

This is beneficial for the spreading of ideas, but we need to stay critical. Even the greatest thinkers are not without flaws. They are mere humans, and they may cherry-pick, make wrong attributions or construct strawmen arguments. Credits are due where they are due, but we must avoid guru-ism that can lead to cultism, halo effects, loss of criticality, acceptance of arguments from authority, and so on. If we do not maintain our ability to think critically, if we do not test and probe the new approaches, we may be developing yet another movement with its own beliefs, dogmas and myths. New dogmas and myths will not contribute to safety science, but rather weaken its credibility - both in general and the credibility of the new approaches. For example, near-miss reporting is increasingly presented as a 'numbers game' and bureaucratic effort (Dekker, 2018). This does reflect the practice in many organisations, and it is necessary to address questionable practices. However, that does not make all near miss reporting useless and presenting only one negative side ignores the original intention and the opportunities it offers (Heinrich, 1931). Here it is necessary that individuals understand the fine details of arguments, but when authors do not provide these, where will practitioners get them from?

\section{EVOLUTION}

\subsection{Drivers, Internal and External}

About 2.500 years ago, the Greek philosopher Heraclitus seems to have said, "Everything changes and nothing stands still" combinations of circumstances, and when they do, they emerge into complex, dynamic environments. This means that there will be many possibilities for the evolution of these concepts, including evolution into directions that we did not intend and maybe even do not approve of at all. Initially, the development and evolution will probably be driven from within the circle of academics and practitioners who have embraced the concepts or are interested in them. They will discuss, try to understand and make sense of things, reframe, refine and adjust the original ideas, and develop tools to support the approach. This rather natural process is part of establishing a movement with new approaches. We can see this for example when we go back a few years and follow the literature on Resilience Engineering from the October 2004 conference in Söderköping ${ }^{* *}$ to the current day.

Evolutionary processes are not limited to 'insiders'. At some point, ideas will attract the interest of others, especially when a concept becomes popular, as it will be discussed in the next section. Unless they remain unknown or are ignored, concepts will take a life of their own, no matter what. Adaptation and change are inevitable - for better and worse. One may have a good idea, but one has no control over the development of the thoughts one puts in the world. Users will give new meanings to and find new applications for concepts ${ }^{\dagger \dagger}$. This includes meanings that were not necessarily intended by their originators. Le Coze illustrates this well with a discussion of popular

\footnotetext{
thttp://www.safetydifferently.com/about/

$\S$ Quoted by Plato in Cratylus, 402a.

** Commonly regarded as the start of Resilience Engineering as a movement.

$\dagger$ 'User-finished design' is a concept well-known in the 'new view' (e.g. Woods \& Dekker, 2000).
} 
safety models by Reason, Rasmussen and Weick and Sutcliffe: "...by making the models their own, these users have become its promoters but also illustrates how models can potentially escape their designers' initial intention." (Le Coze, 2013, p.203).

There are many other examples. One of the oldest is the accident triangle, which evolved from an idea to make accident prevention more proactive, to find improvements before people get hurt (Heinrich, 1931) into a metric that diverts resources from where it matters to places where they do little good (Dekker, 2018). Another is Westrum's typology of organisational cultures (Westrum, 2004). This 'model' has gone through a metamorphosis from a descriptive/educational model (Fleming, 2001) to the Hearts \& Minds tool for self-evaluation (Hudson, 2007), an audit tool, and even a certification scheme to award jobs (NEN, 2016). This is an example of how originally useful ideas are taken over and twisted until they do more harm than good (Busch, 2017); from a safety point of view because users see some value in how they use a tool.

\subsection{Regulations and Legislation}

Another almost inevitable factor of the evolution of new approaches is their encounter with legislators and regulators. Important questions that should be asked - but often are not even considered - are whether these approaches are understood by regulators, whether they are suitable for legislation, regulation and enforcement at all, and, when they are legislated, regulated and enforced, what side effects this can lead to. Recent examples are attempts to 'regulate' (safety) culture in regulations, standards and certification schemes (e.g. Antonsen, et al., 2016; Grote \& Weichbrodt, 2013; Busch, 2017) or the implementation of 'just culture' in EU Regulation 376/2014 It is too early to comment on the effects of the latter, but one may wonder whether this indeed will lead to 'juster cultures' or if it rather will become sticking a 'new view' label on an 'old view' approach of organisational justice and culpability.

\section{SUCCESS}

\subsection{Salonfähigkeit}

Thoughts and concepts that are often initially abstract and 'academic' must be turned into something practical and useful. The German expression "Etwas salonfähig machen" describes this process. In part, one can make something (socially) acceptable by informing and educating the audience. Additionally, to make something suitable for the masses, it often needs some 'watering down' and 'streamlining'. Commercialization is therefore necessary, or at least inevitable, for ideas to spread and get a wider application. A concept must be turned into 'products' (tools to improve work and the like) that can be offered to 'clients'. However, when these 'products' manage to gain greater attraction and interest, increased consumer demand for a product may cause a drive for price rather than quality, as well as an increase of less qualified suppliers who fill gaps between supply and demand and try to get a piece of the cake (Donkin, 2001; Stewart, 2009).

When a Louis Vuitton purse becomes fashionable and is in high demand, others will soon be making purses just like them, or worse, cheap fakes appear that superficially look like the real thing, but are inferior in quality. "Skills diminish when a practice spreads out to a wider audience, where new practitioners enter the market and begin to compete on price. In these circumstances, quality and artistry take a nose-dive" (Donkin, 2001, p.29). One also thinks of Weinberg's 'Law of Raspberry Jam': "The wider you spread it, the thinner it gets" (Weinberg, 1985). Similar processes follow the increasing popularity of management theories and safety approaches (Stewart, 2009), where applications are based on simplified, often dumbed-down versions of the ideas that often follow formulas and rituals while missing the main point. Ironically, success may be one of the greatest risks for the 'new view'.

\footnotetext{
$\$$ https://www.easa.europa.eu/document-library/regulations/regulation-eu-no-3762014
} 


\subsection{Products and Buzzwords}

Turning concepts into products may be necessary for a breakthrough to the mainstream. However, when less-informed suppliers start joining the bandwagon, once useful terms and concepts quickly devaluate into mere buzzwords. Suppliers who are mainly in it for the money can easily repackage and label their old approaches as new ones by connecting it to new fashions and sell their old wine in new skins to uncritical or less informed clients. A recent example is the attempt to claim that Behaviour Based Safety (BBS) was basically the same as HOP (Human \& Organizational Performance) (Williams \& Roberts, 2018).

The 'new view' definitely has several phrases that are crisp, snappy or lend themselves very well to becoming buzzwords. 'Resilience' has already fallen prey to this (Woods, 2015), terms as 'complexity' and 'systems-approach' have great appeal, and as we saw 'just culture' already made it into regulations. The terms 'work-as-done' and 'work-as-imagined' are great candidates for the near future. One wonders how long it will take before we are confronted with a work-as-done checklist, HOP certification, Lean Safety Differently or even an ISO standard for Resilience Management System. The first signs are on the horizon and approaching fast. It is not difficult to imagine the Resilience Analysis Grid (Hollnagel, 2015) transformed into an easy to sell, audit and assessment tool, with certifications done by 'Resilience Black Belts'. Also Training for Operational Resilience Capabilities (TORC) with its board games and story cards (Grøtan \& Van der Vorm, 2015) is not hard to envision to develop into a 'resilience campaign' in line with current 'safety culture' campaigns.

\section{ETHICAL DILEMMAS}

So far, this paper discussed ways in which 'new view' approaches can lead to certain pitfalls. To round off, there can also be possible problems on the individual level. Dilemmas a practitioner may encounter in his or her work.

\subsection{Is the Customer Always Right?}

Dilemmas may deal with very practical issues with a choice between doing what is 'right' (from a professional, scientific, or ethical point of view) versus doing what is 'needed' (from an organisational, political, psychological, or practical point of view) or 'possible' (because of resources or outside expectations). Should one do an investigation in a quick and superficial way to deliver a fast and seemingly conclusive answer, as demanded, or should one insist on mapping the full context and deliver a much more nuanced answer? Management typically wants quick and certain answers rather than nuanced and uncertain ones. The only correct answer to the question "Is this safe?" is most likely "That depends...", but hardly anyone will want to hear this.

At a recent conference, someone remarked, "Today, here with you, I am very critical about the concept of safety culture. But tomorrow, if a client asks me if I can help them with a culture change program, I probably will sell them one". This is not unethical; people do things that make sense to them at the time, and they have to put food on the table. However, it may put the practitioner in an ethical squeeze forcing him or her in a trade-off between clashing beliefs, priorities, politics, theory and practices, and a variety of objectives.

\subsection{Is 'Knowing' Smart?}

Most organisations manage safety through traditional approaches and may have adopted and invested in policies that may be at odds with a 'new view'. How should practitioners who have come to realize that there are other - possibly better - ways to enhance safety deal with this? The path of least resistance would be an "Ignorance is bliss" approach. However, if you know something, you no longer have the excuse of ignorance (Lotto, 2017). Knowing brings the responsibility to act, or at least the feeling that one should act in accordance with own beliefs. 
On the other hand, in many organisations, it may be preferable that one does not upset the status quo, especially when an important part of your safety management is determined by your client, as is not uncommon in for example oil and gas, and construction industry, or through legislation. Also, decisions affecting safety often serve other organisational goals. For example, concluding with 'human error' and appointing blame are problematic from a 'new view' perspective. Still, these are organisationally and politically useful concepts (Cook \& Nemeth, 2010), whether we like it or not.

Experience shows that speaking up can come at high personal costs. Whistleblowers often experience lengthy and stressful processes, become outcasts in their organisation and social environment, may have a hard time finding another job because they have been branded as 'troublemakers', and may even see their family life in ruins (Bjørkelo, 2016; NRK, 2016). Things do not need to be that serious, of course, but still, it may be tough to go against company policy or programs and question established wisdom. Picking one's fights wisely (to paraphrase the quote commonly attributed to Sun Tzu), and bending instead of breaking are probably the best advice. Recognizing the problems but sometimes accepting the situation may be necessary, as is recognizing and using opportunities for interventions.

\section{CONCLUSIONS}

Returning to Huxley's (1932) classic novel, it is to be hoped that new approaches do not end up like John the Savage; misunderstood, frustrated, disillusioned and dead. To be very clear, the author is all in favour of teaching, promoting, spreading and practising new and different approaches to safety. This paper aims to reflect on some possible side effects that may arise and provide challenges. This paper does not offer any ready solutions for the issues raised. To avoid them will be most likely impossible. Ideas and tools cannot be designed such that they will be immune to evolution and developments. Humans are creative and will use ideas and tools in ways that have not been anticipated before. Even though this cannot be prevented, one can be aware that it will happen, and be ready to act.

Safety is about balancing various objectives and being able to handle constant variations. The same applies to professional development. Safety professionals and scholars have to strive for continuous improvement. In this, they have to be aware of pitfalls and side effects and be prepared to deal with the inevitable variations that will occur (and actually are necessary). A balanced approach in the communication and handling of concepts and tools is necessary. As is keeping open minds and staying critical. Critical about established wisdom and traditional approaches, but also critical about our assumptions and beliefs.

\section{ACKNOWLEDGEMENTS}

Thanks to: Nektarios Karanikas and the team for ICSC for providing the opportunity, Martijn Flinterman for ETTO-ing some valuable feedback before the delivery of the final draft;

Jean-Christophe Le Coze for an inspiring presentation on culture and managemet fads at the May 2018 Learning Lab and providing some feedback on the draft; Anthony Smoker and Fabian Landherr for thoughtful comments afterwards. These comments, along with those of anonymous reviewers and the audience at the ICSC 2018 have added greatly to this final version.

\section{REFERENCES}

Antonsen, S., Nilsen, M. \& Almklov, P.G. (2016) Regulating the intangible. Searching for safety culture in Norwegian petroleum industry. Safety Science, 92: 232-240. doi:10.1016/j.ssci.2016.10.013.

Bird jr., F.E. \& Loftus, R.G. (1976) Loss Control Management. Loganville: Institute Press, Inc. Bjørkelo, B. (2016) Whistleblowing: Antecedents and consequences. Psychologia Społeczna, 11 (3): 267-283. 
Busch, C. (2016) Safety Myth 101. Mysen: Mind The Risk.

Busch, C. (2017) Een Ladder op Drijfzand - Een kritische kijk op de Veiligheidsladder. NVVK Info, 26 (2): 18-22.

Cialdini, R.B. (1984) Influence. The Psychology of Persuasion. New York: Harper Collins.

Dekker, S.W.A. (2002) Reconstructing human contributions to accidents: the new view on error and performance. Journal of Safety Research, 33 (3): 371-385.

Dekker, S.W.A. (2014) The Field Guide to Understanding 'Human Error'. Farnham: Ashgate.

Dekker, S.W.A. (2018) The Safety Anarchist. Relying on Human Expertise and Innovation, Reducing Bureaucracy and Compliance. Milton Park: Routledge.

Donkin, R. (2001) Blood Sweat \& Tears. The Evolution of Work. New York: Texere.

Fleming, M. (2001) Safety Culture Maturity Model. Norwich: HSE Books

Gesinger, S. (2018) The Fearless World of Professional Safety in the 21st Century. Milton Park: Routledge.

Grøtan, T.O. \& Van der Vorm, J. (2015) Training for Operational Resilience Capabilities. Presented at 6th Symposium on Resilience Engineering, Lisbon 22-25 June 2015. Resilience Engineering Association.

Grote, G. \& Weichbrodt, J. (2013) Why regulators should stay away from safety culture and stick to rules instead. In Bieder, C. \& Bourrier, M. (ed.) Trapping Safety into Rules: How desirable or avoidable is Proceduralization? Farnham: Ashgate.

Hale, A.R. (2014) Foundations of safety science: A postscript. Safety Science, 67: 64-69. doi: 10.1016/j.ssci.2014.03.001

Harari, Y.N. (2011) Sapiens: A Brief History of Humankind. London: Vintage/Penguin Random House.

Heinrich, H.W. (1931) Industrial Accident Prevention - A Scientific Approach. New York: McGrawHill.

Hollnagel, E. (2009) The ETTO Principle: Efficiency-Thoroughness Trade-Off - Why Things That Go Right Sometimes Go Wrong. Farnham: Ashgate.

Hollnagel, E. (2012) FRAM - The Functional Resonance Analysis Method: Modelling Complex Socio-technological Systems. Farnham: Ashgate.

Hollnagel, E. (2014) Safety I and Safety II: The Past And Future Of Safety Management. Farnham: Ashgate.

Hollnagel, E. (2015) Introduction to the Resilience Analysis Grid (RAG). Retrieved 6 September 2017 from http://erikhollnagel.com/onewebmedia/RAG\%20Outline\%20V2.pdf.

Hudson, P. (2007) Implementing a safety culture in a major multi-national. Safety Science, 45 (6): 697-722. doi: 10.1016/j.ssci.2007.04.005

Huxley, A. (1932) Brave New World. London: Chatto \& Windus.

Le Coze, J-C. (2013) New models for new times. An anti-dualist move. Safety Science, 59: 200218. doi: 10.1016/j.ssci.2013.05.010

Long, R. (2018) Fallibility and Risk. Living with Uncertainty. Kambah, ACT: Scotoma Press.

Lotto, B. (2017) Deviate. The Science of Seeing Differently. New York: Hachette Books.

Marriott, C. (2018) Challenging the Safety Quo. Milton Park: Routledge.

NEN (2016) Certificatischema Veiligheidsladder 4.0. Delft: NEN

NRK (2016) Får ikke ny jobb fordi han varslet i politiet. Retrieved 20 September 2018 from https://www.nrk.no/hordaland/varsleren-ble-skjovet-ut-i-kulden-i-arbeidslivet-1.12854842

Oxford Dictionaries: 2.0 (n.d.) Retrieved 17 September 2018 from https://en.oxforddictionaries.com/definition/2.0.

Petersen, D. (2001) Safety Management: A Human Approach (3rd edition). Des Plaines, IL: American Society of Safety Engineers.

Pink, D.H. (2012) To Sell Is Human: The Surprising Truth About Persuading, Convincing and Influencing Others. New York: Riverhead Books.

Rasmussen, J. (1990) Human Error and the Problem of Causality in Analysis of Accidents. Philosophical Transactions of the Royal Society of London. Series B, Biological Sciences, 327: 449-462. 
Reason, J. (1990) Human Error. Cambridge: Cambridge University Press.

Shorrock, S. (2014) What Safety-II isn't. Retrieved 13 November 2018 from https://humanisticsystems.com/2014/06/08/what-safety-ii-isnt/

Stewart, Matthew (2009) The Management Myth: Debunking Modern Business Philosophy. New York: Norton.

Tetlock, P. \& Gardner, D. (2015) Superforecasting: The Art \& Science of Prediction. New York: Crown Publishers.

Townsend, A.S. (2014) Safety Can't Be Measured: An Evidence-based Approach to Improving Risk Reduction. Farnham: Gower Publishing.

Weinberg, G.M. (1985) The Secrets of Consulting: A Guide to Giving and Getting Advice Successfully. New York: Dorset House Publishing.

Westrum, R. (2004) A typology of organisational cultures. Quality \& Safety in Health Care, 13(Suppl II): ii22-ii27. doi: 10.1136/qshc.2003.009522.

Williams, J. \& Roberts, S. (2018) Integrating the Best of HOP and BBS: A Holistic Approach to Improving Safety Performance. Professional Safety, October 2018, 40-48.

Woods, D.D. \& Dekker, S.W.A. (2000) Anticipating the effects of technological change: A new era of dynamics for human factors. Theoretical Issues in Ergonomics Science, 1 (3): 272-282. doi: 10.1080/14639220110037452

Woods, D.D. (2015) Four concepts for resilience and the implications for the future of resilience engineering. Reliability Engineering \& System Safety, 141: 5-9. doi:

10.1016/j.ress.2015.03.018 